\title{
Vorsorgen für die Zukunft ...
}

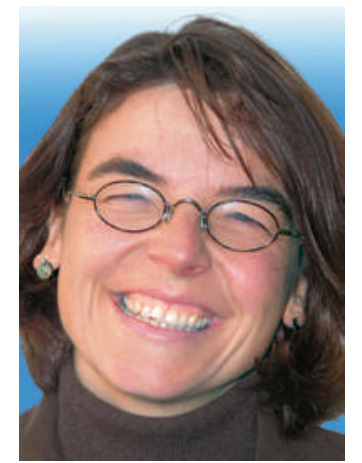

Christina Aus der Au
Ich bin soeben vom Krankenbett wieder aufgestanden. Die Grippe - zum Glück nicht die MagenDarm-Variante, sondern «nur» die mit viel Fieber und Husten. Eine ganze Woche, die gut gefüllt gewesen wäre mit Sitzungen und Retraiten, verschwand im Fieberschlaf. Und die Welt drehte sich trotzdem. Auch ohne mich.

Wieder zurück im Büro begegnete mir viel freundlich-tröstendes Willkommen, aber auch von einigen ein ganz klein bisschen selbstzufriedenes Lächeln: Diese hatten sich gegen diese Grippe geimpft.

Sie haben an allen Sitzungen teilgenommen, sie sind nicht schuld an den krankheitsbedingten Ausfällen in der Wirtschaft, auf sie ist Verlass. Während Leute wie ich den Launen des Körpers unterworfen sind und mein Geist den primitivsten Bedürfnissen des Leibes ausgeliefert war: schlafen, trinken, schlafen.

Nein, ich will hier nicht die Impfdiskussion wieder aufflammen lassen. Ich bin absolut überzeugt, dass es sehr viele gute Gründe gibt, sich gegen die Grippe impfen zu lassen! Bei Berufsgruppen, die mit Kindern und alten Menschen zu tun haben, sowieso, da ist es fast schon egoistisch, wenn man die eigene Krankheitsanfälligkeit ungefiltert an andere weitergibt. Und auch mich hats geärgert, ich habe spannende Sitzungen verpasst, und zum Teil müssen wir jetzt mühsam neue Termine suchen.

Ich bin nicht geimpft. Und ich werde es wahrscheinlich auch jetzt nicht tun. Und auch nächstes Jahr nicht. All meinen rationalen Überlegungen und meinem Ärger zum Trotz. Seltsames Wesen Mensch. Jetzt gäbe es hier ein Mittel, das nicht viel kostet, nach allem menschlichen Wissen und Gewissen mit durchaus akzeptablem Risiko, das mich vor viel Unbill und Scherereien bewahren könnte. Und ich verzichte wissentlich und willentlich darauf. Woran liegt das bloss?

Lasse ich mich - trotz aller Dankbarkeit für den Fortschritt, insbesondere den medizinischen - von einer romantischen Vorstellung von der Natur leiten? Im Sinne von: Der Körper weiss schon, was mir fehlt, die Fiebergrippe ist ein Zeichen dafür, dass ich überarbeitet bin und mir Ruhe gönnen soll? Ist der Bauch schlauer als das Gehirn? Enger verbunden mit meinem wahren Ich?

Oder verweigere ich mich damit der Diktatur des Bruttosozialprodukts? Will ich an der Einsprachemöglichkeit des Körpers festhalten gegenüber dem Zwang zur Effizienz? Geniesse ich etwa unbewusst das erzwungene Nichtstun als Rebellion gegen die durchorganisierte Gesellschaft?
Nein, bei Tageslicht betrachtet sind das wirklich nicht meine Argumente. Ich bin ich, so meine ich, gerne und mit Überzeugung körperlich-leiblich-seelischer Gehirn-Magen-Bauch. Ich teile weder den Glauben an ein wahres Ich im Bauch noch den an das eigentliche Ich im Gehirn. Ich, das empirische, allein vorhandene und vorfindliche Ich, bin ein Konglomerat von allem, und kein Körperteil hat eine tiefere Verankerung mit irgendeiner ausserkörperlichen Wahrheit.

Und ich arrangiere mich sowohl mit dem Terminkalender als auch mit dem Fieberthermometer. Ich arbeite meistens gerne - und alles, was ich letzte Woche nicht erledigt habe, bleibt sowieso auf meinem Schreibtisch liegen.

\section{«Oder verweigere ich mich damit der Diktatur des Bruttosozialprodukts?»}

Warum denn lasse ich mich ums Himmels willen nicht gegen die Grippe impfen?

Wenn ich tief und ehrlich in mich hineinschaue, fürchte ich, die Gründe sind viel prosaischer als die wohlklingenden Argumente, die ich versuchsweise auf den Tisch gelegt habe. Ich bin einfach zu träge, um überall die Kontrolle haben zu wollen. Ich bin zu faul, um heute schon für morgen zu planen. Jetzt bin ich nicht mehr krank, jetzt ist die Grippe wieder in weiter Ferne. In der Gegenwart leben heisst, die Zukunft ausblenden. Sie jedenfalls nicht in die Gegenwart hineinwirken lassen. Und schon gar nicht die Gegenwart auf die Zukunft ausrichten.

Ein kleiner Piks hätte mir viel erspart. Würde mir viel ersparen. Aber ich verdränge auch diesmal die Sache wieder. Ich kann mir vorstellen, wie schwierig es sein kann, die Leute zu Vorsorgeuntersuchungen zu bewegen. Oder gar dazu, ihr gegenwärtiges Verhalten zu ändern, um zukünftig besser, gesünder, länger zu leben. Als Individuen und als Menschheit. Wir sind einfach Gegenwartswesen, die Zukunft ist viel weniger real.

Aber nun liegt meine kleine Tochter mit der Grippe darnieder. Zukunft, die jetzt schon Gegenwart ist. Hätte ich mich doch impfen lassen sollen?

Christina Aus der $A u^{*}$ der Au ist an der Abteilun Systematische Theologie / Basel tätig und Mitglied der zeitung. 